\title{
Prostate-specific antigen and free prostate-specific antigen/prostate-specific antigen ratio in patients with benign prostatic hyperplasia and prostate cancer
}

\author{
Amal A. Hussein ${ }^{1}$, Rayah S. Baban ${ }^{2}$ and Alaa G. Hussein ${ }^{3}$ \\ ${ }^{1}$ Laboratory of Clinical Biochemistry, Al-Imamain Al-Kadhimain Medical City, Baghdad, Iraq \\ ${ }^{2}$ Department of Chemistry and Biochemistry, College of Medicine, Al-Nahrain University, Baghdad 70036, Iraq \\ ${ }^{3}$ Department of Pathology, College of Medicine, Al-Nahrain University, Baghdad, Iraq
}

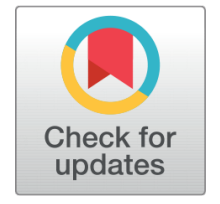

Received 22-08-2020

Revised 01-09-2020

Accepted 20-12- 2020

Published 25-12-2020

\section{Corresponding Author}

Amal A. Hussein

am87al78am@yahoo.com

Laboratory of Clinical

Biochemistry, Al-Imamain

Al-Kadhimain Medical City,

Baghdad, Iraq

DOI https://doi.org/10.47419/ bjbabs.v1i01.28

\section{Pages: 18-26}

Distributed under the terms of the Creative Commons

Attribution-NonCommercial 4.0 International (CC-BY-NC 4.0), which permits use for any non-commercial purpose, distribution, and reproduction in any medium, provided that the original work is properly cited.

Copyright: (c) 2020 Amal A. Hussein, Rayah S. Baban, Alaa G. Hussein

\section{ABSTRACT}

Background: Prostate cancer is one of the most common cancers in men, worldwide. Many markers are suggested for prostate cancer with different specificity and sensitivity.

Objectives : This study is aimed is to examine the possible utility of prostate-specific antigen indices as markers of prostate cancer.

Methods: A case-control study was conducted in the Department of Chemistry and Biochemistry, College of Medicine, Al-Nahrain University, Baghdad, Iraq from July 2018 till March 2019, includes 84 subjects divided into three groups: twenty-four patients with prostate cancer (PCA), thirty patients with benign prostatic hyperplasia $(\mathrm{BPH})$ and thirty healthy subjects as a control group were examined in this study. Blood samples from all participants were collected, and before obtaining a prostatic biopsy from patients. Serum prostate-specific antigen (PSA) and free prostate-specific antigen (fPSA) levels were quantified by the ELISA technique. Results: PSA cut-off value was found to be more than $9.57 \mathrm{ng} / \mathrm{ml}$ for PCA patients, values range between $3.17-9.57 \mathrm{ng} / \mathrm{ml}$ for BPH patients and cut-off value for control was found to be less than $3.17 \mathrm{ng} / \mathrm{ml}$, while serum (fPSA/PSA)\% cut-off value was less than $11.1 \%$ for PCA patients, values range between $11.1 \%-31 \%$ for $\mathrm{BPH}$ patients, and cut-off value was greater than $31 \%$ for the control group.

Conclusion: There is a highly significant difference in serum PSA levels and (fPSA/PSA)\% between the PCA and control groups. Body mass index showed an inverse association with the risk of prostate cancer.

Keywords benign prostatic hyperplasia, body mass index, free prostatespecific antigen, prostate cancer, prostatespecific antigen, receiver operating characteristic curve

\section{OPEN ACCESS}




\section{INTRODUCTION}

Prostate cancer is the leading cancer death in men, it rates vary more than 25 -fold worldwide, with the highest rates in North America, Western and Northern Europe, Australia, and New Zealand. There are also relatively high rates in the Caribbean, South America, and South Africa and lower rates across Asia and Eastern Europe. ${ }^{1}$

According to the Annual Report of Iraqi Cancer Registry in 2016; the prostate cancer incidence rate of cases in 2016 shows that the highest percentage and incidence for top ten cancers in 2016 in both genders was among the breast cancer and the lowest was among the prostate cancer with incidence rate accounts for 4.1 incidence rate (per 100,000 population) of top ten cancer in the male in Iraq in $2016 .^{2}$ According to recent studies, PSA fails to consider as an accurate PCA predictive biomarker (limited by poor specificity). The main problem is the hurdles in differentiation between $\mathrm{BPH}$ and prostate cancer, it is Prostate tissuespecific and not prostate cancer-specific biomarker test so, a substantial interference in PSA values between cancerous and non-cancerous individuals. ${ }^{3}$ Considerable efforts have been made to find new biomarkers for the accurate diagnosis of prostate cancer. ${ }^{4}$

Results of numerous studies have been conducted on the relationship between BMI and PCa was associated with the risk of prostate cancer have not been consistent. ${ }^{5}$ According to the World Health Organization, the BMI was divided into six categories. ${ }^{6}$ This research aims to measure the PSA indices in patients with Prostate Cancer and Benign Prostatic Hyperplasia.

\section{METHODS}

\section{Study design and participants}

This case-control study was conducted from August 2018 till February 2019. patients who were recruited to Al-Imamain AL-Kadhimain Medical City, Al- Shahid Ghazi AlHariri Specialized Surgery Hospital/ Urology Consultation Unit, Al-Amal National Hospital for Cancer Management in Baghdad city. The study includes 84 samples divided into three groups:

- Twenty four patients with prostate cancer (PCA).

- Thirty patients with benign prostatic hyperplasia (BPH).

- Thirty healthy subjects (as control group).

The age was ranged between 50- 81 years old. The patients with prostate cancer and benign prostatic hyperplasia were included in the current study; while patients with prostatitis, sexually transmitted infections, patients with chronic renal failure, Patients on finasteride or, dutasteride therapy for the prostatic disease were excluded. A blood sample was aspirated using disposable syringes in the sitting position. The blood is discharged slowly into plain disposable test tubes without anticoagulant, until it clot for 15 minutes at room temperature, then centrifuged at $1000_{x} \mathrm{~g}$ for 10 minutes. Serum PSA and free PSA were estimated 
by using the ELISA technique. FPSA\% levels were calculated according to the following equation (fPSA / total PSA) X 100, ${ }^{7}$ Body Mass Index (BMI) was calculated using the belowmentioned equation. According to the World Health Organization, the BMI was divided into six categories. ${ }^{6}$

$B M I=\frac{(\text { Weight in } K g)}{(\text { Height in })^{2}}$

\section{Statistical analysis}

The results obtained in this study were expressed as mean \pm SEM, and statistical comparisons were conducted with the use of independent t-test for comparing two independent groups (patients and controls). Analysis of variance (ANOVA) test for comparison among more than 2 groups using Tukey HSD post-Hoc test to assess the significant differences between studied subgroups; considered $\mathrm{p}<0.05$ as statistically significant. The Pearson correlation test tested correlations among all studied parameters, and all statistical analyses used in this study were carried out by using the IBM SPSS Statistics for Windows, Version 20.0 (Armonk, NY: IBM Corp). The normality of distribution was checked using ShapiroWilk and Kolmogorov- Smirnov tests.

Receiver operating characteristic (ROC) analyses were accomplished as a comprehensive way to determine the accuracy of the markers used in this study. In ROC analysis, the area under the curve (AUC) can be considered as a powerful statistical tool for comparing different biomarkers given the value of AUC that becomes closer to one indicates that the parameter can be considered as an excellent diagnostic and predictive biomarker, a curve obtained in this statistical analysis may indicate the significance of the marker. So, the curve of a parameter that lies close to the diagonal $(\mathrm{AUC}=0.5)$ shows no diagnostic importance. An AUC value that is closer to one is always coupled with sensitivity and specificity satisfactory values. ${ }^{8}$

\section{RESULTS}

There was a significantly high difference $(P<0.001)$ among all study groups regarding serum PSA and (fPSA/PSA) \% levels. Prostate-specific antigen shows a very highly significant increase $(\mathrm{P} 1<0.001 ; \mathrm{P} 3<0.001)$ between Prostate Cancer group in comparison with the both control group and Benign Prostatic Hyperplasia group respectively, while there was no significant difference (P2=0.859) between Benign Prostatic Hyperplasia group versus the control group as shown in Table 1 . There was a very high significant decrease $(\mathrm{P} 1<0.001)$ $(\mathrm{P} 3<0.001)$ in $(\mathrm{fPSA} / \mathrm{PSA}) \%$ values between Prostate Cancer group in comparison with the control group and Benign Prostatic Hyperplasia groups respectively; in contrast, no significant decrease $(\mathrm{P} 2=0.416)$ was found between Benign Prostatic Hyperplasia group against the control group (Table 1).

The mean \pm SEM of BMI in $\left(\mathrm{kg} / \mathrm{m}^{2}\right)$ for Prostate Cancer group was $25.49 \pm 0.62$, and 28.28 \pm 0.80 for Benign Prostatic Hyperplasia group, while for control group it was 
$27.81 \pm 0.47 \mathrm{~kg} / \mathrm{m}^{2}$. A highly significant difference $(\mathrm{P} \leq 0.01)$ was found between all study groups. A high significant difference was found between the control group and patients groups (BPH and PCA); a significant difference (P1=0.016) was found between Control group versus Prostate Cancer group, as well as between Prostate Cancer group versus Benign Prostatic Hyperplasia group ( $\mathrm{P} 3=0.004)$ while no significant difference ( $\mathrm{P} 2=0.599)$ was found between Control group versus Benign Prostatic Hyperplasia group, as shown in Table 1.

The mean \pm SEM of age in years for the control group was $53.40 \pm 0.68$, and $64.77 \pm 1.56$ for Benign Prostatic Hyperplasia group, while $70.17 \pm 1.38$ for Prostate Cancer group respectively (Table 1).

\begin{tabular}{|c|c|c|c|c|c|c|c|}
\hline Characteristic & $\begin{array}{l}\text { PCA } \\
(n=24)\end{array}$ & $\begin{array}{l}\text { BPH } \\
(n=30)\end{array}$ & $\begin{array}{c}\text { Control } \\
(n=30)\end{array}$ & $\mathbf{P}$ & P1 & P2 & P3 \\
\hline Age (years) & $70.17 \pm 1.38$ & $64.77 \pm 1.56$ & $53.40 \pm 0.68$ & $<0.001^{\dagger H S}$ & $<0.001 €_{H S}$ & $<0.001 €_{H S}$ & $0.004^{€_{H S}}$ \\
\hline BMI $\left(\mathrm{kg} / \mathrm{m}^{2}\right)$ & $25.49 \pm 0.62$ & $28.28 \pm 0.80$ & $27.81 \pm 0.47$ & $0.010^{\dagger H S}$ & $0.016^{€ H S}$ & $0.599^{€ N S}$ & $0.004^{€ H S}$ \\
\hline PSA (ng/ml) & $124.12 \pm 21]$. & $5.12 \pm 0.50$ & $2.57 \pm 0.11$ & $<0.001^{\dagger H S}$ & $<0.001^{€_{H S}}$ & $0.859^{€ N S}$ & $<0.001^{€ H S}$ \\
\hline (fPSA/PSA)\% & $11.00 \pm 1.39$ & $26.71 \pm 2.42$ & $24.45 \pm 1.90$ & $<0.001^{\dagger H S}$ & $<0.001^{€_{H S}}$ & $0.416^{€ N S}$ & $<0.001^{€ H S}$ \\
\hline
\end{tabular}

n: number of cases; $\uparrow$ : One way ANOVA; $€$ : post hoc LSD test; HS: highly significant at $P \leq 0.01$; NS: not significant at $P \leq 0.05$; S: significant at $P \leq 0.05$; P1: $P$-value for control vs carcinoma; P2: $P$-value for control vs BPH; P3: $P$-value for carcinoma vs $\mathrm{BPH}$.

To compare the validity measurement among all the biomarkers and specify the most suitable cut-off value for each biomarker, a receiver operating characteristic (ROC) curve was established. This was applied to locate the most viable biomarkers as a panel of performed biomarkers tool for participating in the detection of Prostate Cancer.

The validity indicators such as sensitivity, specificity and area under curve (AUC) for the present diagnostic biomarkers; serum PSA and (fPSA/PSA) \%, based on receiver operating characteristic (ROC) curve (Figure 1) were calculated and illustrated in Table 2.

Regarding PCA group versus non-cancerous subjects, including BPH group and healthy men group as the selection of control subjects in this study were done by choosing healthy men with normal serum PSA level. Thus, according to ROC curve of serum PSA level, the cut-off value $>9.57 \mathrm{ng} / \mathrm{ml}$ optimally identified the patients with Prostate Cancer from those who are non-cancerous; at this cut-off value the sensitivity was $87.5 \%$, specificity was $100 \%$, and the area under curve AUC was 0.983. A very highly significant increase $(P<0.001)$ was found between Prostate Cancer group versus non-cancerous group. Regarding serum fPSA/PSA\% level, the cut-off value $\leq 11.1$ optimally identified the patients with Prostate Cancer from those who are non-cancerous; at this cut-off value the sensitivity was $75 \%$, specificity was $98.33 \%$, and the area under curve AUC was 0.888. A very high significant decrease $(P<0.001)$ was found for Prostate Cancer group versus non-cancerous group (Table 2).

As shown in table (3) and figure (2), regarding $\mathrm{BPH}$ group versus control group, based on ROC curve of serum PSA level, the cut-off value $>3.17 \mathrm{ng} / \mathrm{ml}$ optimally identified the 
Table 2 Cut off value, sensitivity, specificity and area under curve (AUC) of receiver operating characteristic (ROC) curve of prostate-specific antigen (PSA) and (fPSA/PSA)\% in prostate cancer versus non-cancerous groups.

$\begin{array}{lll}\text { Characteristic } & \text { PSA }(\mathbf{n g} / \mathbf{m l}) & \text { fPSA/PSA (\%) } \\ \text { Cut-off value } & >9.57 & \leq 11.1 \\ \text { AUC } & 0.983 & 0.888 \\ \text { Sensitivity } & 87.5 & 75 \\ \text { Specificity } & 100 & 98.33 \\ \text { P-value } & <\mathbf{0 . 0 0 1} & <\mathbf{0 . 0 0 1}\end{array}$

PSA: Prostate specific antigen; (fPSA/PSA)\%: free prostate specific antigen/prostate specific antigen\%; $\boldsymbol{P}$ value: highly significant at $P \leq 0.001$; significant at $P \leq 0.05$.

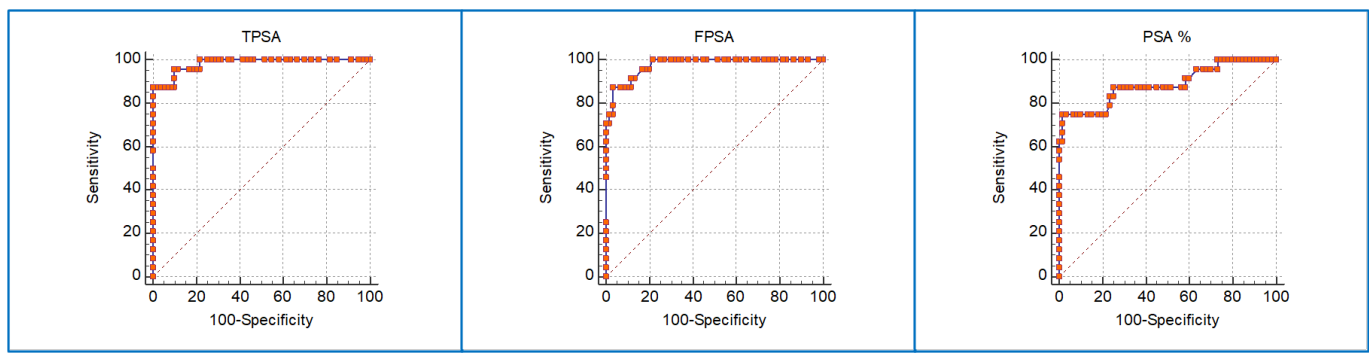

Figure 1 Receiver operating characteristic curve of prostate-specific antigen (PSA), free prostatespecific antigen \%(fPSA/PSA)\% in cancer versus non-cancerous group
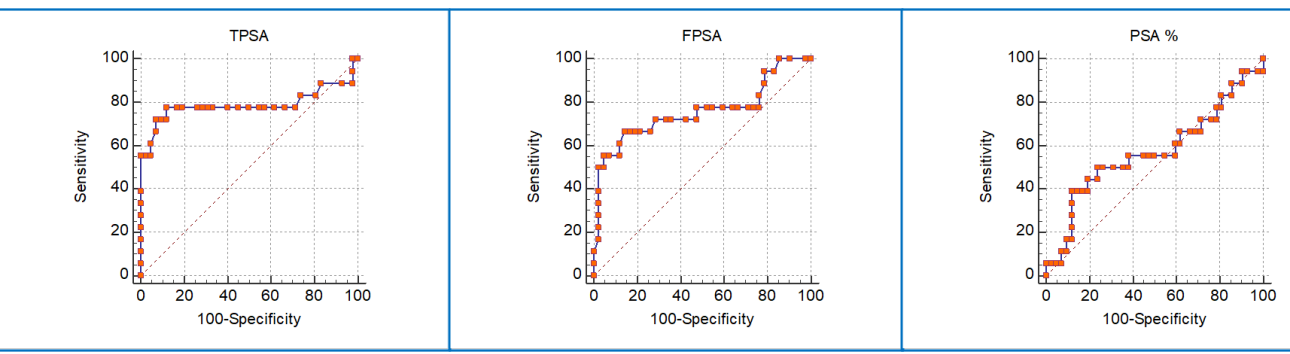

Figure 2 Receiver operating characteristic curve for total prostate-specific antigen (PSA), free prostatespecific antigen \% (fPSA/PSA)\% in benign prostatic hyperplasia group versus the control group.

patients with $\mathrm{BPH}$ from those who are healthy men; at this cut-off value the sensitivity was $77.78 \%$, specificity was $88.1 \%$, and the area under curve AUC was 0.789 . A very highly significant increase $(P<0.001)$ was found between the $\mathrm{BPH}$ group versus the control group.

Regarding, serum (fPSA/PSA)\% level, the cut-off value $\leq 31$ optimally identified the patients with $\mathrm{BPH}$ from those who are healthy men; at this cut-off value the sensitivity was $38.89 \%$, specificity was $88.1 \%$, and the area under curve AUC was 0.57 . There was no significant difference $(\mathrm{P}=0.436)$ between the $\mathrm{BPH}$ group versus the control group (Table (3) and figure (2)). 
The cut- off values of PSA based on the ROC curve results in the current study was 9.57 $\mathrm{ng} / \mathrm{ml}$ for Prostate cancer patients, while its value range between $9.57-3.17 \mathrm{ng} / \mathrm{ml}$ for BPH patients, and $<3.17 \mathrm{ng} / \mathrm{ml}$ for apparently healthy men respectively, and the cut-off value of serum fPSA /PSA\% level was 11.1\% for Prostate cancer patients, range between 11.1\% -31 $\%$ for $\mathrm{BPH}$ patients, and $>31 \%$ for apparently healthy men respectively.

Table 3 Cut off value, sensitivity, specificity and area under curve (AUC) of receiver operating characteristic (ROC) curve of prostate-specific antigen (PSA) and (fPSA/PSA)\% in BPH group versus the control group

$\begin{array}{lll}\text { Characteristic } & \text { PSA }(\mathbf{n g} / \mathbf{m l}) & \text { fPSA/PSA ( \%) } \\ \text { Cut-off } & >3.17 & <31 \\ \text { AUC } & 0.789 & 0.57 \\ \text { Sensitivity } & 77.78 & 38.89 \\ \text { Specificity } & 88.1 & 88.1 \\ \text { P-value } & \mathbf{0 . 0 0 1} & \mathbf{0 . 4 3 6}\end{array}$

PSA: Prostate Specific Antigen; fPSA/PSA\%: free Prostate Specific Antigen/Prostate Specific Antigen \%; Pvalue: very higg significant at $P \leq 0.001$; significant at $P \leq 0.05$.

\section{DISCUSSION}

Prostate cancer incidence rates racially vary by more than 25 fold worldwide, explained by lifestyle and genetic differences; it is highest in Australia/New Zealand, Northern America, Northern and Western Europe and some Caribbean nations and lowest in Asia. ${ }^{9,10}$

According to Iraqi Cancer Registry in 2016; the highest percentage and incidence was present among the breast cancer, and the lowest rate was found among the Prostate cancer. The Incidence Rate (Per 100, 000 Population) of top ten Cancer in males in Iraq in 2016 for Prostate Cancer is $4.13 .^{2}$

Prostate Cancer is one of the most controversial health care issues because of the dilemmas related to diagnosis using Prostate Specific Antigen PSA. A high number of falsepositive biopsies and an elevated rate of over diagnosis are the main problems associated with PSA. New PCA biomarkers have been recently proposed to increase the predictive value of PSA. ${ }^{11}$ In the European Randomized Study of Screening for Prostate Cancer (ERSPC) including 162,387 men, PSA test showed 75.9\% false-positive results. ${ }^{12}$ Such false prediction rate can be explained by several factors, for example, enlarged prostate gland such as benign prostatic hyperplasia (BPH) may lead to the increase in PSA level, but no cancer was detected. ${ }^{13}$ Moreover, the PSA level is higher with older age; ${ }^{14}$ besides, high BMI decreases PSA level. ${ }^{15}$ In 2018, the European Randomized Study of Prostate Cancer concluded a high incidence of over-diagnosis, the Prostate Cancer Prevention Trial suggested that there is no a definite PSA threshold with high sensitivity and specificity. ${ }^{16}$

The findings of the current study based on receiver operation characteristic (ROC) curve in a sample of Iraqi patients show that the PSA cut-off value was $9.57 \mathrm{ng} / \mathrm{ml}$ for Prostate Cancer patients. According to the American Cancer Society, PSA level above $4 \mathrm{ng} / \mathrm{mL}$ and 
below $10 \mathrm{ng} / \mathrm{mL}$ have $25 \%$ chance of PCA occurrence and PSA level more than $10 \mathrm{ng} / \mathrm{mL}$ increases chances of PCA occurrence over $50 \% .{ }^{13}$ Although PSA is considered as the best biomarker for the diagnosis of PCA, it is still far from being the ideal biomarker due to the fact that there is no accurate threshold that can be used with relative security for the diagnosis of PCA.

On the other hand, the use of the (fPSA/tPSA)\% ratio has been shown to improve specificity in the detection of prostate cancer. No definitive data are available indicating the optimal (fPSA/tPSA)\% that should be applied, ${ }^{17}$ in the present study; The cut-off value of free Prostate Specific Antigen percentage (fPSA\%) based on the ROC curve results finding was $\leq 11.1 \%$ for Prostate cancer patients.

Researchers have conducted cohort and case-control studies involving diverse populations to determine the relationship between prostate cancer and obesity, measured in terms of body mass index (BMI). BMI show inverse correlation with risk of prostate cancer, the results were in agreement with Shannon et al. ${ }^{18}$ and disagree with others, ${ }^{19,20}$ who concluded that (BMI) has been associated with increased prostate cancer risk, while Lee et al. analysis showed no evidence that body weight was associated with prostate cancer. ${ }^{21}$ Also, Giovannucci et al. concluded that no relationship exists between BMI and prostate cancer among older males (age $>60$ years). ${ }^{5}$ It can be concluded that although there is a highly significant difference of serum PSA levels among all the study groups, there is no definite value that can be used for detection and discrimination between men with and without prostate cancer. Also, the results of BMI showed an inverse correlation with risk of prostate cancer.

The present study demonstrated that the (fPSA/PSA) \% ratio was a strong predictor of future cancer detection and ominous cancerous signs in prostate biopsy in men with total PSA levels of $2.1-10.0 \mathrm{ng} / \mathrm{ml}$ at population screening.

\section{ACKNOWLEDGMENTS}

The authors gratefully acknowledge the Department of Chemistry and Biochemistry, College of Medicine, Al-Nahrain University staff for their help.

\section{DECLARATIONS}

\section{Authors' contributions}

All authors have equally contributed to this work.

\section{Conflict of interest}

The authors declare that there is no conflict of interest.

\section{Ethical approvals}

The institutional review board of the College of Medicine and Al-Imamain Al-Kadhimain Medical City approved this study. Informed consent were obtained from each participant before collecting the samples. 


\section{Data availability}

The data associated with this work can be requested from the corresponding author.

\section{Funding resources}

This work didn’t receive any fund.

\section{REFERENCES}

1. Sritharan J. Investigating the Occupational Etiology of Prostate Cancer in Canadian Men. University of Toronto; 2018.

2. Planning Directorate, Ministry of Health / Environment, Republic of Iraq; 2016.

3. Spyropoulos E. Considerations Regarding the Predictive Value of PSA Testing, as a Diagnostic Tool for Prostate Cancer in the Current Clinical Practice. Clin Oncol. 2017;2:1-3.

4. Lazzeri M, Lughezzani G, Haese A, McNicholas T, de la Taille A, Buffi NM, et al. Clinical performance of prostate health index in men with tPSA $>10 \mathrm{ng} / \mathrm{ml}$ : Results from a multicentric European study. Urologic Oncology: Seminars and Original Investigations. 2016;34(9):415.e13-415.e19. Available from: 10.1016/j.urolonc.2016. 04.003; https://dx.doi.org/10.1016/j.urolonc.2016.04.003.

5. Giovannucci E, Rimm EB, Liu Y, Leitzmann M, Wu K, Stampfer MJ, et al. Body Mass Index and Risk of Prostate Cancer in U.S. Health Professionals. JNCI Journal of the National Cancer Institute. 2003;95(16):1240-1244. Available from: 10.1093/ jnci/djg009; https://dx.doi.org/10.1093/jnci/djg009.

6. Garvey WT, Mechanick JI, Brett EM, Garber AJ, Hurley DL, Jastreboff AM, et al. American association of clinical endocrinologists and American College of Endocrinology comprehensive clinical practice guidelines for medical care of patients with obesity. Endocrine Practice. 2016;22(Supplement 3):1-203. Available from: 10.4158/ep161365.gl.

7. Nan LB, Yin XT, Gao JP. Significant Diagnostic Value of Free-Serum PSA (FPSA)/Prostate-Specific Antigen Density (PSAD) and (F/T)/PSAD for Prostate Cancer of the Chinese Population in a Single Institution. Med Sci Monit. 2019;25:8345-8351.

8. Hajian-Tilaki K. Receiver operating characteristic (ROC) curve analysis for medical diagnostic test evaluation. Casp J Intern Med. 2013;4:627-635.

9. Tan L, Tan Y, Tai B, Tan K, Gauhar V, Tiong H, et al. Prospective validation of \%p2PSA and the Prostate Health Index, in prostate cancer detection in initial prostate biopsies of Asian men, with total PSA 4-10 ng ml-1. Asian Journal of Andrology. 2017;19(3):286-286. Available from: 10.4103/1008-682x.168687;https: //dx.doi.org/10.4103/1008-682x.168687.

10. Park H, Lee SW, Song G, Kang TW, Jung JH, Chung HC, et al. Diagnostic performance of \%[-2]proPSA and prostate health index for prostate cancer: Prospective, multi-institutional study. J Korean Med Sci. 2018;33:94-94. 
11. Filella X, Foj L. Novel biomarkers for prostate cancer detection and prognosis. Adv Exp Med Biol. 2018;p. 15-39.

12. Eckersberger E, Finkelstein J, Sadri H, Margreiter M, Taneja SS, Lepor H, et al. Screening for Prostate Cancer: A Review of the ERSPC and PLCO Trials. Rev Urol. 2009;11:127-133.

13. Akizhanova M, Iskakova EE, Kim V, Wang X, Kogay R, Turebayeva A, et al. PSA and Prostate Health Index based prostate cancer screening in a hereditary migration complicated population: implications in precision diagnosis. Journal of Cancer. 2017;8(7):1223-1228. Available from: 10.7150/jca.18012; https://dx.doi.org/10. $7150 /$ jca.18012.

14. Barqawi AB, Golden BK, O’Donnell C, Brawer MK, Crawford ED. Observed effect of age and body mass index on total and complexed PSA: Analysis from a national screening program. Urology. 2005;65(4):708-712. Available from: 10.1016/ j.urology.2004.10.074;https://dx.doi.org/10.1016/j.urology.2004.10.074.

15. Wright JL, Lin DW, Stanford JL. The effect of demographic and clinical factors on the relationship between BMI and PSA levels. The Prostate. 2011;71(15):1631-1637. Available from: 10.1002/pros.21380; https://dx.doi.org/10.1002/pros.21380.

16. Skarmoutsos A, Skarmoutsos I, Katafigiotis I, Tataki E, Giagini A, Alamanis C, et al. Detecting Novel Urine Biomarkers for the Early Diagnosis of Prostate Cancer: Platelet Derived Growth Factor-BB as a Possible New Target. Current Urology. 2018;12(1):13-19. Available from: 10.1159/000447225; https://dx.doi.org/10.1159/ 000447225.

17. Erol B, Gulpinar MT, Bozdogan G, Ozkanli S, Onem K, Mungan G, et al. The cutoff level of free/total prostate specific antigen ( $\mathrm{f} / \mathrm{t}$ PSA) ratios in the diagnosis of prostate cancer: A validation study on a Turkish patient population in different age categories. The Kaohsiung Journal of Medical Sciences. 2014;30(11):545-550. Available from: 10.1016/j.kjms.2014.03.008;https://dx.doi.org/10.1016/j.kjms.2014.03.008.

18. Shannon J, Palma AJ, Peters L, Garzotto M. Body mass index, PSA, and prostate cancer risk. Journal of Clinical Oncology. 2008;26(15_suppl):5159-5159. Available from: 10.1200/jco.2008.26.15_suppl.5159;https://dx.doi.org/10.1200/jco.2008. 26.15_suppl.5159.

19. Pergola GD, Silvestris F. Obesity as a Major Risk Factor for Cancer. Journal of Obesity. 2013;2013:1-11. Available from: 10.1155/2013/291546;https://dx.doi.org/10.1155/ 2013/291546.

20. Allott EH, Masko EM, Freedland SJ. Obesity and Prostate Cancer: Weighing the Evidence. European Urology. 2013;63(5):800-809. Available from: 10.1016/j.eururo. 2012.11.013;https://dx.doi.org/10.1016/j.eururo.2012.11.013.

21. Lee IM, Sesso HD, Paffenbarger RS. A prospective cohort study of physical activity and body size in relation to prostate cancer risk (United States). Cancer Causes Control. 2001;12:187-193. 